\title{
Burnout and Associated Risk Factors in Pediatric Residents
}

\author{
Abdulmajeed Bin Dahmash, MBBS, Mohammed Faisal Alajmi, MBBS, Abdulrahman Yousef Aldayel, MBBS, Yasir \\ Tariq Alotaibi, MBBS, Sultan Meshal Altoum, MBBS, Abdullah Alzayed, MBBS, Moslah Ali Jabari, MBBS \\ Department of Pediatrics, College of Medicine, Imam Mohammad ibn Saud Islamic University, Riyadh, Saudi Arabia
}

Background: Burnout is a syndrome characterized by emotional exhaustion, depersonalization, and a low sense of personal accomplishment. The aim of this study was to identify burnout incidence in pediatric residents and evaluate possible risk factors for burnout.

Methods: Using a cross-sectional study design, we approached all pediatric residents in the Saudi Pediatrics Residency Program in Riyadh, Saudi Arabia $(n=457)$ between January and March 2019. The Maslach Burnout Inventory-Human Services Survey was used to assess burnout incidence. In addition, demographic factors, schedule burden, career choice satisfaction, and work-life balance were assessed.

Results: The response rate was $57.8 \%$ (264/457). Males represented $46.6 \%$. Only $14 \%$ of the residents in the study were satisfied with their work-life balance, and $62 \%$ were satisfied with their career choice of pediatrics. The overall high burnout incidence was $15.9 \%$, the high emotional exhaustion incidence was $63.6 \%$, the high depersonalization incidence was $27.7 \%$, and the low sense of personal accomplishment incidence was $48.5 \%$. In the multivariate analysis, an increase in the average number of on-calls per month (odds ratio $[O R]=1.66,95 \% \mathrm{Cl} 1.12-2.46 ; P=0.012$ ) and satisfaction with salary $(\mathrm{OR}=0.47,95 \% \mathrm{Cl} 0.33-0.66 ; P<0.001)$ showed significant associations with high overall burnout.

Conclusion: We found a high level of emotional exhaustion and a low sense of personal accomplishment among respondents. However, less than one-third of residents had feelings of depersonalization or overall high burnout. Residency program directors may need to make modifications in their programs to ensure a good work-life balance for residents that will help ensure that these physicians provide safe and sustained patient care.

Keywords: Burnout-professional, burnout-psychological, internship and residency, pediatrics, work-life balance, workplace

Address correspondence to Moslah Ali Jabari, Department of Pediatrics, College of Medicine, Imam Mohammad ibn Saud Islamic University, Othman Bin Affan Rd., Al-Nada-7544, Riyadh 13317-4233, Saudi Arabia. Tel: +966 1120 37100. Email: m.peds.de@gmail.com

\section{INTRODUCTION}

Practicing medicine while studying can be challenging, and studies have shown that the incidence of burnout among pediatric residents ranges from $17 \%$ to $67.8 \% .{ }^{1}$ Burnout is a syndrome characterized by emotional exhaustion, depersonalization, and a low sense of personal accomplishment. ${ }^{2}$ Symptoms include anger, blame, helplessness, hopelessness, treating patients as impersonal objects, loneliness, and frustration with patients and with the health care system. ${ }^{3}$ Overburdened schedules, increased on-call scheduling, lack of mentorship, an unsupportive family or partner, dissatisfaction with work-life balance, and a lack of self-care are all risk factors that can precipitate burnout. ${ }^{4-6}$

Physicians with burnout are in danger of making medical errors and have lower patient satisfaction rates than nonburned-out physicians. ${ }^{7,8}$ While burnout has been investigated in many specialties, burnout among pediatric residents in Saudi Arabia has been recognized only recently
(2018). ${ }^{9}$ A single-center study of 32 pediatric residents in Jeddah, Saudi Arabia, showed high emotional exhaustion in $43 \%$ of participants. ${ }^{9}$ Understanding burnout incidence and the risk factors among residents can help residency program directors control the working environment to create a support system that can reduce burnout incidence. ${ }^{6}$

Residency is a stressful phase in a physician's career and an ideal time to implement personal and organizational plans to decrease burnout incidence. ${ }^{10}$ We investigated burnout among pediatric residents in Saudi Arabia using a validated measure. We also evaluated possible risk factors, including demographic factors, schedule burden, lack of career choice satisfaction, and work-life balance.

\section{METHODS}

Institutional review board approval was obtained from the College of Medicine, Imam Mohammad ibn Saud Islamic University, for this quantitative cross-sectional study. We 
distributed a survey to all pediatric residents in the city of Riyadh ( $n=457)$ between January and March 2019. The survey was distributed to residents during their academic activities at each center and was collected at the end of the activities. The first page of the survey included a description of the study and a consent form. We did not ask for the name of the resident or any detail that could reveal the resident's identity. Participation was totally voluntary.

The first part of the survey collected demographic information (age, sex, marital status, and residency level/ postgraduate year), health-related factors (smoking status, hours of sleep/day, exercise days/week), and workrelated factors (average on-calls/month, average working hours/day, number of clinics/week, and average number of patients under daily care). Satisfaction with work-life balance, choice of pediatrics as a career, and salary was measured using a 5-point Likert-type scale ranging from 1 ("very satisfied") to 5 ("very unsatisfied"). Prior to the analysis, scores were recoded so that 5 corresponded to very satisfied and 1 corresponded to very unsatisfied. The second part of the survey was the Maslach Burnout Inventory-Human Services Survey (MBI-HSS), a validated measure of burnout. ${ }^{11}$

The MBI-HSS includes 22 questions that evaluate 3 domains of burnout: emotional exhaustion (9 questions), depersonalization (5 questions), and sense of personal accomplishment (8 questions). The severity of each item is assessed on a 7-point Likert scale, ranging from 0 ("never") to 6 ("always"). Higher emotional exhaustion and depersonalization scores are associated with higher levels of burnout, whereas higher personal accomplishment scores are associated with lower levels of burnout. High emotional exhaustion was defined as a score $>26$, and high depersonalization was defined as a score $>12$. Low sense of personal accomplishment was defined as a score $<32$. A high risk of burnout was defined as coexisting high emotional exhaustion, high depersonalization, and low sense of personal accomplishment.

Statistical analysis was performed using SPSS, version 24.0 (IBM Corp). Counts and percentages were used to summarize participant demographics. Mean $\pm S D$ was used to summarize continuous variables. Burnout dimensions and overall burnout were analyzed as continuous and categorical (dichotomous) variables based on the previously mentioned cutoff criteria. Likert-scale items - satisfaction with worklife balance, career choice, and salary-were summarized using counts and percentages. Binary logistic regression was used to assess the predictors of the burnout dimensions as well as overall burnout. Univariate binary logistic regression was used to assess the associations of demographics and residency-related factors with burnout. Four models were constructed, 1 for each of the 3 dimensions of burnout and 1 for overall burnout. In addition, a chi-square test of independence was used to assess whether the distribution of each dependent variable across the various demographics was significantly different from what was expected under the null hypothesis. Multivariate binary logistic regression was used to assess the independent predictors of high risk of burnout. All independent variables were initially included in the model. A backward approach (using the $P$ value for the Wald chi-square statistic) was used for variable selection. Variables were kept in the model if the $P$ value for the multivariate Wald chi-square statistic in the final model was $<0.1$. Two-tailed hypothesis testing was performed at
Table 1. Demographic Characteristics of the Pediatric Resident Respondents $(n=264)$

\begin{tabular}{|c|c|}
\hline Variable & Value \\
\hline \multicolumn{2}{|l|}{ Age, years, n (\%) } \\
\hline$<25$ & $7(2.7)$ \\
\hline $25-27$ & $173(65.5)$ \\
\hline $28-30$ & 79 (29.9) \\
\hline $31-33$ & $3(1.1)$ \\
\hline $34-36$ & $2(0.8)$ \\
\hline \multicolumn{2}{|l|}{ Sex, n (\%) } \\
\hline Female & $141(53.4)$ \\
\hline Male & $123(46.6)$ \\
\hline \multicolumn{2}{|l|}{ Marital status, n (\%) } \\
\hline Unmarried & $173(65.5)$ \\
\hline Married & $91(34.5)$ \\
\hline \multicolumn{2}{|l|}{ Residency year, n (\%) } \\
\hline 1 & $108(40.9)$ \\
\hline 2 & $75(28.4)$ \\
\hline 3 & $45(17.0)$ \\
\hline 4 & $36(13.6)$ \\
\hline \multicolumn{2}{|l|}{ Smoking status, n (\%) } \\
\hline No & $198(75.0)$ \\
\hline Yes & $66(25.0)$ \\
\hline \multicolumn{2}{|l|}{ Exercise, n (\%) } \\
\hline Never & $139(52.7)$ \\
\hline$\geq 1$ day/week & $125(47.3)$ \\
\hline Hours of sleep/day, mean \pm SD & $6.15 \pm 1.33$ \\
\hline Number of on-calls/month, mean \pm SD & $5.16 \pm 0.91$ \\
\hline $\begin{array}{l}\text { Number of hours working in the hospital/day, } \\
\text { mean } \pm S D\end{array}$ & $8.81 \pm 2.31$ \\
\hline Number of clinics/week, mean \pm SD & $2.29 \pm 2.95$ \\
\hline Number of patients under daily care, mean \pm SD & $5.63 \pm 3.71$ \\
\hline
\end{tabular}

$\alpha \leq 0.05$. Odds ratios (ORs) and $95 \%$ Cls were calculated for the independent variables included in the analysis. Exercise, age, and residency level were dichotomized prior to the analysis. The dichotomized versions of the burnout dimensions were handled as dependent variables. Satisfaction levels with work-related aspects were treated as continuous variables. Model performance was assessed by using $R^{2}$ (the proportion of variance explained by the independent variables).

\section{RESULTS}

Of the 457 surveys distributed, 264 surveys were returned for a response rate of $57.8 \%$. Demographic characteristics of the respondents are shown in Table 1. Satisfaction with work-life balance, career, and salary is shown in the Figure.

High emotional exhaustion was reported by $63.6 \%$ of residents $(n=168)$, while a low sense of personal accomplishment was expressed by $48.5 \%(n=128)$. High depersonaliza- 
How satisfied are you with your work-life balance?

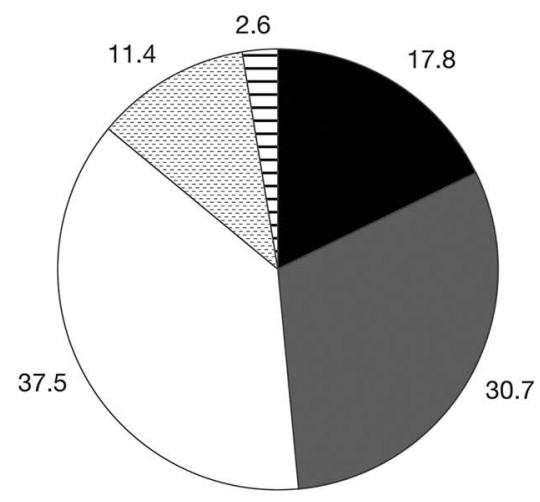

Very unsatisfied
How satisfied are you with pediatrics as a career?
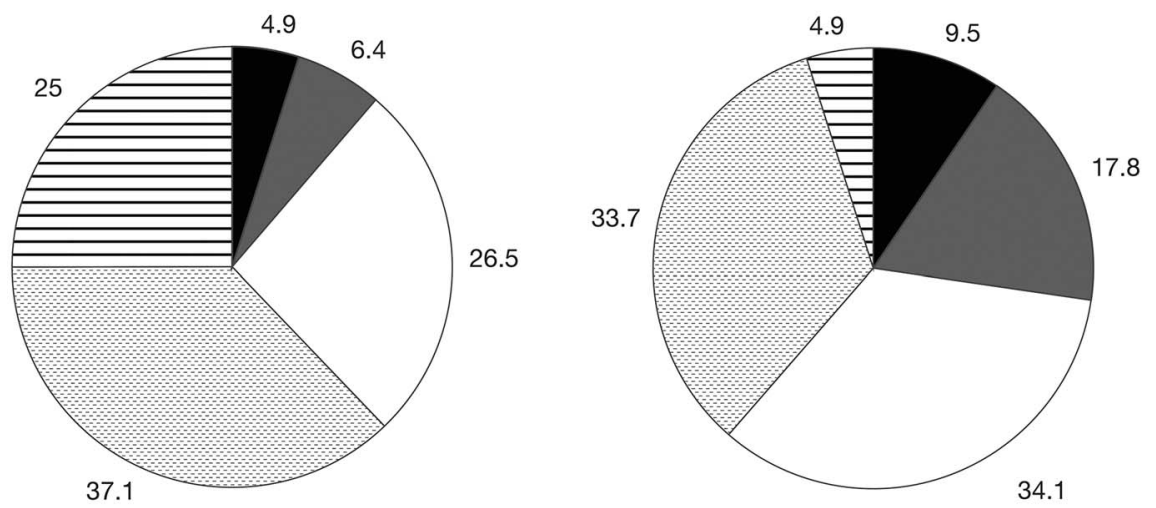

How satisfied are you with your job salary?

Somewhat unsatisfied Neutral Somewhat satisfied Very satisfied

Figure 1. Respondents' satisfaction with work-life balance, career choice of pediatrics, and salary.

tion was the least prevalent of all burnout dimensions $27.7 \%$ $(n=73)$. High risk of overall burnout was present in $15.9 \%$ $(n=42)$ of the pediatric residents in this study (Table 2$)$.

Univariate logistic regression analysis (data not shown) showed that having more on-calls/month $(\mathrm{OR}=1.58,95 \%$

Table 2. Mean Scores for Burnout Domains, Prevalence of Negative Scores, and Prevalence of Overall High Burnout Among Pediatric Residents $(n=264)$

\begin{tabular}{lc}
\hline Variable & Value \\
\hline Continuous presentation, mean \pm SD (range) & \\
Emotional exhaustion & $30.8 \pm 11.6(2-54)$ \\
Depersonalization & $9.51 \pm 5.91(1-26)$ \\
Sense of personal accomplishment & $30.9 \pm 8.45(8-47)$ \\
Categorical presentation, n (\%) & \\
High emotional exhaustion & \\
No & $96(36.4)$ \\
Yes & $168(63.6)$
\end{tabular}

High depersonalization

$\begin{array}{ll}\text { No } & 191(72.3) \\ \text { Yes } & 73(27.7)\end{array}$

Low personal accomplishment

$\begin{array}{ll}\text { No } & 136(51.5) \\ \text { Yes } & 128(48.5)\end{array}$

High burnout

No

Yes

$42(15.9)$

Notes: High emotional exhaustion was defined as a score $>26$, high depersonalization was defined as a score $>12$, and low sense of personal accomplishment was defined as a score $<32$. High burnout was defined as coexisting high emotional exhaustion, high depersonalization, and low personal accomplishment.
Cl 1.17-2.12; $P=0.003$ ) and more patients under daily care $(\mathrm{OR}=1.09,95 \% \mathrm{Cl} 1.01-1.19 ; P=0.035)$ were both significantly associated with high emotional exhaustion. The probability of high emotional exhaustion increased by $58 \%$ for each additional on-call in the month. Similarly, the probability of high emotional exhaustion increased by $9 \%$ for each additional patient under the daily care of a pediatric resident in this study. None of the remaining work-related variables showed a statistically significant association with emotional exhaustion.

High depersonalization was associated significantly only with the average number of on-calls/month $(\mathrm{OR}=1.57$, $95 \% \mathrm{Cl} 1.14-2.15 ; P=0.005)$ (data not shown). None of the remaining work-related variables showed a statistically significant association with depersonalization. None of the work-related variables showed a statistically significant association with low sense of personal accomplishment.

Table 3 shows the association of demographic and work-related variables with high overall burnout. More oncalls/month was significantly associated with the risk of high burnout $(\mathrm{OR}=1.88,95 \% \mathrm{Cl} 1.27-2.77 ; P=0.001)$. The probability of burnout increased by $88 \%$ for each increase in on-calls/month. None of the remaining variables was significantly associated with high risk of burnout.

As shown in Table 4, high satisfaction with job salary was associated with lower odds of high emotional exhaustion $(\mathrm{OR}=0.50,95 \% \mathrm{Cl} 0.38-0.67 ; P<0.001)$. For each 1 unit increase in satisfaction with job salary, the odds of high emotional exhaustion decreased by $50 \%$. Similarly, for each 1-unit increase in satisfaction with job salary, the odds of high depersonalization also decreased by approximately 50\% (OR=0.52, 95\% Cl 0.39-0.68; $P<0.001)$. A 1 unit increase in job satisfaction score was associated with a $32 \%$ decrease in the odds of low sense of personal accomplishment $(\mathrm{OR}=0.68,95 \% \mathrm{Cl} 0.53-0.87 ; P=0.002)$. Overall, the odds of high burnout decreased by $56 \%$ for each $1-$ unit increase in satisfaction with job salary $(\mathrm{OR}=0.44,95 \% \mathrm{Cl}$ 0.32-0.62; $P<0.001)$. 
Bin Dahmash, $A$

Table 3. Association of Demographic and Work-Related Factors With High Burnout

\begin{tabular}{|c|c|c|c|c|}
\hline Variable & High Burnout $n=42$ & Odds Ratio (95\% Cl) & $P$ Value (LR) ${ }^{a}$ & $P$ Value $^{\text {b }}$ \\
\hline Age, years, n (\%) & & & & 0.501 \\
\hline$<28$ & $31(73.8)$ & Reference & Reference & \\
\hline$\geq 28$ & $11(26.2)$ & $0.73(0.33-1.50)$ & 0.403 & \\
\hline Sex, n (\%) & & & & 0.982 \\
\hline Female & $23(54.8)$ & Reference & Reference & \\
\hline Male & $19(45.2)$ & $0.94(0.48-1.83)$ & 0.852 & \\
\hline Marital status, n (\%) & & & & 0.994 \\
\hline Unmarried & $27(64.3)$ & Reference & Reference & \\
\hline Married & $15(35.7)$ & $1.07(0.52-2.12)$ & 0.846 & \\
\hline \multicolumn{5}{|l|}{ Residency year, n (\%) } \\
\hline 1 and 2 & $33(78.6)$ & Reference & Reference & 0.217 \\
\hline 3 and 4 & $9(21.4)$ & $0.58(0.25-1.23)$ & 0.158 & \\
\hline Smoking status, n (\%) & & & & 1.000 \\
\hline No & $31(73.8)$ & Reference & Reference & \\
\hline Yes & $11(26.2)$ & $1.09(0.49-2.26)$ & 0.833 & \\
\hline Exercise, n (\%) & & & & 0.640 \\
\hline Never & $24(57.1)$ & Reference & Reference & \\
\hline$\geq 1$ days/week & $18(42.9)$ & $0.81(0.41-1.57)$ & 0.532 & \\
\hline Hours of sleep/day, mean \pm SD & $6.24 \pm 1.51$ & $1.06(0.83-1.35)$ & 0.646 & 0.681 \\
\hline Number of on-calls/month, mean $\pm S D$ & $5.57 \pm 0.99$ & $1.88(1.27-2.77)$ & 0.001 & 0.004 \\
\hline Number of hours working in the hospital/day, mean \pm SD & $8.79 \pm 0.84$ & $1.00(0.86-1.15)$ & 0.948 & 0.906 \\
\hline Number of clinics/week, mean $\pm S D$ & $2.05 \pm 2.88$ & $0.97(0.86-1.09)$ & 0.565 & 0.560 \\
\hline Number of patients under daily care, mean \pm SD & $6.17(3.63)$ & $1.04(0.96-1.13)$ & 0.314 & 0.305 \\
\hline
\end{tabular}

Note: High burnout was defined as coexisting high emotional exhaustion, high depersonalization, and low personal accomplishment.

aUnivariate logistic regression (LR).

${ }^{\mathrm{b}}$ Chi-square test (categorical variables) or $t$ test (continuous variables).

Each 1-unit increase in satisfaction with the choice of pediatrics as a career was associated with a $53 \%$ decrease in the odds of high emotional exhaustion $(\mathrm{OR}=0.47,95 \%$ Cl $0.35-0.64 ; P<0.001)$, a $29 \%$ decrease in the odds of high depersonalization (OR=0.71, 95\% Cl 0.55-0.92; $P=0.008)$, a $45 \%$ decrease in the odds of low sense of personal accomplishment $(\mathrm{OR}=0.55,95 \% \mathrm{Cl} 0.43-0.71 ; P<0.001)$, and an overall $41 \%$ decrease in the odds of high burnout $(\mathrm{OR}=0.59$, 95\% Cl 0.44-0.79; $P=0.001)$.

Each 1-unit increase in satisfaction with work-life balance was significantly associated with lower likelihood of high emotional exhaustion $(P<0.001)$, high depersonalization $(P<0.001)$, low sense of personal accomplishment $(P=0.006)$, and high burnout $(P<0.001)$.

As displayed in Table 5, male respondents were at lower risk of high emotional exhaustion than females $(\mathrm{OR}=0.51$, 95\% $\mathrm{Cl} 0.29-0.99 ; P=0.025)$, and the risk of high emotional exhaustion was 2.5 times higher in smokers compared to nonsmokers $(\mathrm{OR}=2.49,95 \% \mathrm{Cl}, 1.12-5.53 ; P=0.046)$. Each 1 -call increase in the average number of on-calls/month was associated with a $59 \%$ increase in the odds of high emotional exhaustion $(\mathrm{OR}=1.59 ; 95 \% \mathrm{Cl}, 1.09-2.31, P=0.015)$.

Table 4. Univariate Logistic Regression Analysis of Career Variable Satisfaction and Burnout Domains and High Burnout

\begin{tabular}{|c|c|c|c|c|c|c|c|c|}
\hline \multirow[b]{2}{*}{ Career Variable } & \multicolumn{2}{|c|}{$\begin{array}{l}\text { High Emotional } \\
\text { Exhaustion }\end{array}$} & \multicolumn{2}{|c|}{$\begin{array}{c}\text { High } \\
\text { Depersonalization }\end{array}$} & \multicolumn{2}{|c|}{$\begin{array}{c}\text { Low Personal } \\
\text { Accomplishment }\end{array}$} & \multicolumn{2}{|c|}{$\begin{array}{l}\text { High } \\
\text { Burnout }\end{array}$} \\
\hline & OR (95\% Cl) & $P$ Value & OR (95\% CI) & $P$ Value & OR (95\% CI) & $P$ Value & OR (95\% CI) & $P$ Value \\
\hline Salary & $0.50(0.38-0.67)$ & $<0.001$ & $0.52(0.39-0.68)$ & $<0.001$ & $0.68(0.53-0.87)$ & 0.002 & $0.44(0.32-0.62)$ & $<0.001$ \\
\hline Pediatrics career & $0.47(0.35-0.64)$ & $<0.001$ & $0.71(0.55-0.92)$ & 0.008 & $0.55(0.43-0.71)$ & $<0.001$ & $0.59(0.44-0.79)$ & 0.001 \\
\hline Work-life balance & $0.28(0.20-0.41)$ & $<0.001$ & $0.48(0.35-0.65)$ & $<0.001$ & $0.70(0.55-0.90)$ & 0.006 & $0.42(0.29-0.63)$ & $<0.001$ \\
\hline
\end{tabular}

Notes: Odds ratios (ORs) and 95\% Cls represent each 1-unit increase in satisfaction for the career variables. High burnout was defined as coexisting high emotional exhaustion, high depersonalization, and low personal accomplishment. 
Table 5. Multivariate Logistic Regression Analysis Results

\begin{tabular}{|c|c|c|c|c|c|c|c|c|}
\hline \multirow[b]{2}{*}{ Variable } & \multicolumn{2}{|c|}{$\begin{array}{l}\text { High Emotional } \\
\text { Exhaustion }\end{array}$} & \multicolumn{2}{|c|}{$\begin{array}{c}\text { High } \\
\text { Depersonalization }\end{array}$} & \multicolumn{2}{|c|}{$\begin{array}{c}\text { Low Personal } \\
\text { Accomplishment }\end{array}$} & \multicolumn{2}{|c|}{$\begin{array}{c}\text { High } \\
\text { Burnout }\end{array}$} \\
\hline & OR $(95 \% \mathrm{Cl})$ & $P$ Value & OR $(95 \% \mathrm{Cl})$ & $P$ Value & OR $(95 \% \mathrm{Cl})$ & $P$ Value & OR $(95 \% \mathrm{Cl})$ & $P$ Value \\
\hline \multicolumn{9}{|l|}{ Sex } \\
\hline Male & $0.51(0.29-0.99)$ & 0.025 & & & & & & \\
\hline \multicolumn{9}{|l|}{ Smoking status } \\
\hline Yes & $2.49(1.12-5.53)$ & 0.046 & & & & & & \\
\hline \multicolumn{9}{|l|}{ Residency year } \\
\hline 3 and 4 & & & $0.49(0.25-0.97)$ & 0.04 & & & & \\
\hline $\begin{array}{l}\text { Number of } \\
\text { on-calls/month }\end{array}$ & $1.59(1.09-2.31)$ & 0.015 & & & & & $1.66(1.12-2.46)$ & 0.012 \\
\hline Salary satisfaction & $0.62(0.44-0.88)$ & 0.007 & $0.61(0.45-0.82)$ & 0.001 & & & $0.47(0.33-0.66)$ & $<0.001$ \\
\hline $\begin{array}{l}\text { Pediatrics career } \\
\text { satisfaction }\end{array}$ & & & & & $0.55(0.43-0.71)$ & $<0.001$ & & \\
\hline $\begin{array}{l}\text { Work-life balance } \\
\text { satisfaction }\end{array}$ & $0.34(0.23-0.49)$ & $<0.001$ & $0.57(0.41-0.8)$ & 0.001 & & & & \\
\hline$R^{2}$ & $37.7 \%$ & & $13.9 \%$ & & $12 \%$ & & $19.1 \%$ & \\
\hline
\end{tabular}

Notes: Only variables included in the final model using stepwise backward elimination are displayed. High burnout was defined as coexisting high emotional exhaustion, high depersonalization, and low personal accomplishment.

OR, odds ratio; $R^{2}$, coefficient of determination or the proportion of variance in the dependent variable that is explained by the model.

Each 1-unit increase in satisfaction with salary was associated with a $38 \%$ decrease in the odds of high emotional exhaustion $(\mathrm{OR}=0.62,95 \% \mathrm{Cl} 0.44-0.88 ; P=0.007)$. Each $1-$ unit increase in satisfaction with work-life balance was associated with a $66 \%$ decrease in the odds of high emotional exhaustion $(\mathrm{OR}=0.34,95 \% \mathrm{Cl} 0.23-0.49 ; P<0.001)$.

Year 3 and 4 residents were at lower risk of high depersonalization than year 1 and 2 residents $(O R=0.49,95 \%$ $\mathrm{Cl} 0.25-0.97 ; P=0.04)$. Each 1 -unit increase in satisfaction with job salary was associated with a $39 \%$ decrease in the odds of high depersonalization $(\mathrm{OR}=0.61,95 \% \mathrm{Cl} 0.45$ $0.82 ; P=0.001)$. Similarly, each 1-unit increase in satisfaction with work-life balance was associated with a $43 \%$ decrease in the odds of high depersonalization $(\mathrm{OR}=0.57,95 \% \mathrm{Cl}$ $0.41-0.80 ; P=0.001$ )

Each 1-unit increase in satisfaction with career choice of pediatrics was associated with a $45 \%$ reduction in the odds of low sense of personal accomplishment $(\mathrm{OR}=0.55,95 \%$ Cl 0.43-0.71; $P<0.001)$.

Each 1-call increase in the average number of oncalls/month was associated with a $66 \%$ increase in the odds of high burnout $(\mathrm{OR}=1.66,95 \% \mathrm{Cl} 1.12-2.46 ; P=0.012)$, and each 1-unit increase in satisfaction with salary was associated with a $53 \%$ reduction in the odds of high burnout $(\mathrm{OR}=0.47,95 \% \mathrm{Cl} 0.33-0.66 ; P<0.001)$.

\section{DISCUSSION}

Burnout-a constellation of emotional exhaustion, a state of depersonalization, and a diminished feeling of achievement-is caused by interactions between environmental stressors and genetic tendencies. ${ }^{5}$ Burnout can lead to physical and psychological symptoms, as well as substance abuse. All of these factors can negatively affect the life quality of residents and impact their ability to provide competent and safe patient care while meeting their responsibilities to study and learn. ${ }^{5}$ The Accreditation Council for Graduate Medical Education has stated that general practice residents, a group that includes pediatric residents, are among the medical education learners most affected by burnout. ${ }^{12}$

The prevalence of emotional exhaustion and low sense of personal accomplishment among the residents sampled for our study was $63.6 \%$ and $48.5 \%$, respectively. These findings are similar to those of previous studies. ${ }^{13-15}$ Depersonalization was the least prevalent of the 3 dimensions of burnout. The incidence of high burnout was $15.9 \%$ among the respondents. In a large review, McKinley et al showed that the prevalence of burnout varies between $17 \%$ and $67.8 \%$ among pediatric residents. ${ }^{1}$ Pantaleoni et al found that burnout increases from $17 \%$ to $46 \%$ between the start of residency and the mid-intern level. ${ }^{16}$ However, in our multivariate regression analyses (Table 5), we found no significant differences between the year 1 and 2 residents and year 3 and 4 residents in prevalence of high burnout. The number of on-calls showed a significant association with high burnout. In a study of medical and surgical residents at 3 hospitals in Saudi Arabia, Hameed et al found that increased working hours/week was significantly associated with burnout. ${ }^{17}$ Kassam et al studied resident physicians at the University of Calgary in Canada to assess predictors of well-being and demonstrated that personal burnout and work dissatisfaction were the only significant indicators of overall well-being. ${ }^{18}$ However, on-calls affected residents' sleep quality and minimized their leisure and family time.

Study limitations include the use of a survey that creates a dependence on self-reported data at risk for bias. Moreover, data were collected from one city only. An additional limitation of this study is the high proportion of first- and 
second-year residents relative to the higher levels. The Saudi Commission for Health Specialties (SCFHS) - which is responsible for all residency programs in Saudi Arabiasignificantly increased the number of residents accepted in 2017 and 2018, and that increase may be the reason for the higher number of year 1 and 2 residents vs year 3 and 4 residents included in this study. Another limitation is that residents who experienced preexisting anxiety, depression, or other mood-related disorders were not excluded from participation. Also, as with all cross-sectional studies, this study offers relationships but is unable to posit causation. Thus, prospective cohort studies should be conducted to verify the outcomes reported.

An advantage of this study is its sample size that reflects a representative cross-section of pediatric residents in the capital city of Saudi Arabia. Although survey respondents were residents from different pediatric residency programs in Riyadh, Saudi Arabia, we did not intend to compare the results from each residency program. This study illustrates the incidence of burnout in pediatric residents overall, and SCFHS can potentially use this understanding of burnout among pediatric residents to create standardized organizational plans for all residency programs to improve residents' well-being.

\section{CONCLUSION}

Saudi pediatric residents reported high levels of emotional exhaustion and a low sense of personal accomplishment, although less than one-third of residents had feelings of depersonalization or overall high burnout. These findings suggest that residency program directors need to make adjustments to ensure a better work-life balance for residents, which would promote safe and sustained patient care. Prospective studies involving a large cohort of residents from different medical and surgical specialties and from a variety of regions are needed to reproduce these outcomes and to identify other factors that drive burnout.

\section{ACKNOWLEDGMENTS}

The authors wish to express their admiration to all the pediatric residents who participated in this study. The authors have no financial or proprietary interest in the subject matter of this article.

\section{REFERENCES}

1. McKinley TF, Boland KA, Mahan JD. Burnout and interventions in pediatric residency: a literature review. Burn Res. 2017;6:9-17. doi: 10.1016/j.burn.2017.02.003

2. Maslach C, Jackson SE, Leiter MP. Maslach Burnout Inventory. 3rd ed. Consulting Psychologists Press; 1996.

3. Meier DE, Back AL, Morrison RS. The inner life of physicians and care of the seriously ill. JAMA. 2001;286(23):3007-3014.

doi: 10.1001/jama.286.23.3007
4. Bin Dahmash A, Alorfi FK, Alharbi A, Aldayel A, Kamel AM, Almoaiqel M. Burnout phenomenon and its predictors in radiology residents. Acad Radiol. 2020;27(7):1033-1039. doi: 10.1016/j.acra.2019.09.024

5. Ishak WW, Lederer S, Mandili C, et al. Burnout during residency training: a literature review. $J$ Grad Med Educ. 2009;1(2):236-242. doi: 10.4300/JGME-D-09-00054.1

6. Spickard A Jr, Gabbe SG, Christensen JF. Mid-career burnout in generalist and specialist physicians. JAMA. 2002;288(12):1447-1450. doi: 10.1001/jama.288.12.1447

7. Wright AA, Katz IT. Beyond burnout - redesigning care to restore meaning and sanity for physicians. N Engl J Med. 2018;378(4):309-311. doi: 10.1056/NEJMp1716845

8. Panagioti M, Panagopoulou E, Bower $\mathrm{P}$, et al. Controlled interventions to reduce burnout in physicians: a systematic review and meta-analysis. JAMA Intern Med. 2017;177(2):195-205. doi: 10.1001/jamainternmed.2016.7674

9. Jamjoom RS, Park YS. Assessment of pediatric residents burnout in a tertiary academic centre. Saudi Med J. 2018;39(3):296-300.

10. West CP, Dyrbye LN, Erwin PJ, Shanafelt TD. Interventions to prevent and reduce physician burnout: a systematic review and meta-analysis. Lancet. 2016;388(10057):2272-2281. doi: 10.1016/S0140-6736(16)31279-X

11. Maslach C, Jackson SE. The measurement of experienced burnout. J Organ Behav. 1981;2(2):99-113. doi: 10.1002/job.4030020205

12. Accreditation Council for Graduate Medical Education. Committee CLER: Pathways to Excellence. 2013:204-205.

13. Bin Dahmash A, Alhadlaq AS, Alhujayri AK, Alkholaiwi F, Alosaimi NA. Emotional intelligence and burnout in plastic surgery residents: is there a relationship? Plast Reconstr Surg Glob Open. 2019;7(5):e2057. doi: $10.1097 / G O X .0000000000002057$

14. Peterlini M, Tibério IFLC, Saadeh A, Pereira JCR, Martins MA. Anxiety and depression in the first year of medical residency training. Med Educ. 2002;36(1):66-72. doi: 10.1046/j.1365-2923.2002.01104.x

15. Yaghmour NA, Brigham TP, Richter T, et al. Causes of death of residents in ACGME-accredited programs 2000 through 2014: implications for the learning environment. Acad Med. 2017;92(7):976-983. doi: 10.1097/ACM.0000000000001736

16. Pantaleoni JL, Augustine EM, Sourkes BM, Bachrach LK. Burnout in pediatric residents over a 2-year period: a longitudinal study. Acad Pediatr. 2014;14(2):167-172. doi: 10.1016/j.acap.2013.12.001

17. Hameed TK, Masuadi E, Al Asmary NA, Al-Anzi FG, Al Dubayee MS. A study of resident duty hours and burnout in a sample of Saudi residents. BMC Med Educ. 2018;18(1):180. doi: 10.1186/s12909-018-1300-5

18. Kassam A, Horton J, Shoimer I, Patten S. Predictors of well-being in resident physicians: a descriptive and psychometric study. J Grad Med Educ. 2015;7(1):70-74. doi: 10.4300/JGME-D-14-00022.1

This article meets the Accreditation Council for Graduate Medical Education and the American Board of Medical Specialties Maintenance of Certification competencies for Medical Knowledge, Professionalism, and Systems-Based Practice.

C2021 by the author(s); licensee Ochsner Journal, Ochsner Clinic Foundation, New Orleans, LA. This article is an open (i) access article distributed under the terms and conditions of the Creative Commons Attribution (CC BY) license (creativecommons.org/licenses/by/4.0/legalcode) that permits unrestricted use, distribution, and reproduction in any medium, provided the original author(s) and source are credited. 